\title{
IMPACT OF SPILLWAY CONVERSION ON FLOW CHARACTERIS
}

Gamal M. Abdel aal, Maha R. Fahmy, Eslam E. El-Tohamy

\begin{abstract}
Conversed spillway may be some-times considered the best shape from the application point of view accor dam site. The main function of spillway is energy dissipation. So studying the effect of the spillway conver: energy dissipation is very important, In this study the downstream width and the angle of conversion wer experimentally. The dimensional analysis was used to correlate the different parameters affecting the stud phenomena. Beside that the continuity and one-dimension al momentum equation were used to calculate to derive a theoretical equation for the tail water depth. Also, an equation for the loss of energy was denv energy conseration equation It was found that conversion decreases energy dissipation and increases dow water depth. The theoretical results were found to be in a good agreement with the experimental data. Fin results of this study could be recommended in the field of applications.
\end{abstract}

